\title{
RPG E LITERATURA NA ESCOLA: LEITURA, AFETO E NEGOCIAÇÕES DE SENTIDO
}

\section{RPG AND LITERATURE AT SCHOOL: READING, AFFECTION AND MEANING NEGOTIATION}

\author{
Sheila Oliveira LIMA* \\ Franciela Silva ZAMARIAM***
}

\begin{abstract}
Resumo: $\mathrm{O}$ artigo apresenta uma alternativa para a formação de leitores na educação básica por meio de metodologia estruturada a partir do diálogo entre a prática da leitura e a vivência do RPG; discute também as relações dos processos de significação ocorridos nessas duas atividades. Para tanto, apresenta a descrição de campanhas de um RPG baseado na obra "A cartomante", de Machado de Assis, realizadas com alunos do Ensino Médio de uma escola de Londrina. A partir do desenvolvimento observado nas partidas, verifica-se a proximidade entre os fenômenos da leitura e do jogo, além de registrar a subjetividade como elemento fundamental em ambos. Tais constatações levam a uma reflexão a respeito da necessidade de se criarem instrumentos adequados para a mediação entre leitor e texto literário, os quais passam pelo compartilhamento da interpretação (COLOMER, 2009) e pela aproximação afetiva entre leitor e obra (BARTHES, 2004). O texto baseia-se também em estudos sobre a leitura (JOUVE, 2002) e sobre o jogo (CAILLOIS, 1990).
\end{abstract}

Palavras-chave: Leitura. Ensino. Literatura. RPG. Subjetividade.

Abstract: Reading literary texts still seems to be a big challenge in basic education. Seeking to develop a methodology that could solve that problem, this paper presents a proposal based on the practice of reading and playing RPG and their ways of creating meanings. It presents RPG campaigns based on Machado de Assis's short story "A cartomante" ("The fortune-teller"), carried out with high school students in Londrina, Brazil. By observing some matches, it was possible to see similarities between reading and playing as well as the role subjectivity plays in both of them. These findings are the basis for a reflection about the need to create appropriate tools to mediate the interaction between readers and literary texts, which should include sharing interpretations (Colomer) and reader and work affective approximation (Barthes). The research is also based on studies about reading (Jouve) and games (Caillois).

Keywords: Reading. Teaching. Literature. RPG. Subjectivity.

\section{Introdução}

Já não se discute a importância da leitura, mesmo entre leigos, mas, contraditoriamente, formar leitores tem sido uma tarefa exaustiva, com resultados pouco satisfatórios, tanto pelas condições políticas e estruturais em que se encontram as escolas públicas, quanto pela carência

\footnotetext{
* Professora da Universidade Estadual de Londrina (UEL). Doutorado em Linguagem e Educação pela Universidade de São Paulo (USP). E-mail: sheilalima@uel.br.

** Mestre em Estudos da Linguagem pela Universidade Estadual de Londrina (UEL). Email: belamesquita@hotmail.com. ORCID: https://orcid.org/0000-0001-6985-9479.
} 
formativa dos próprios profissionais que atuam na Educação Básica, devido a inúmeros motivos, historicamente constituídos.

Tratando, especificamente, da leitura literária, podemos dizer que esse é um fenômeno complexo: contempla o objeto livro, o ato de ler, os caminhos percorridos pelo leitor durante a realização dessa ação, para, só então, resultar em um “texto-leitura"” (BARTHES, 2004, p. 27), muitas vezes, diferente para cada leitor. Entretanto, apenas o resultado de uma leitura ideal é medido, em avaliações escolares e provas externas, com testes que não dão conta de abarcar a plurissignificação da literatura nem a subjetividade do leitor, justamente, porque descartam o processo da leitura, o percurso de quem leu. É esse descarte que resgatamos neste artigo, por entendermos sua relevância no estudo da formação leitora. Em outras palavras, temos como objetivo analisar os elementos constituintes da leitura através das lentes do RPG (Role Playing Game, ou Jogo de Interpretação de Papéis), demonstrando a semelhança entre os mecanismos do jogo e da leitura.

Desse modo, debruçamo-nos sobre alguns elementos que compõem o fenômeno da leitura, os quais buscamos compreender por meio da análise de três sessões de RPG, criado em $2016^{2}$ para este fim, com base no enredo do conto "A cartomante", de Machado de Assis. Baseando-nos na obra de Picard (1986), sob a ótica de Jouve (2002), cuja atenção está voltada para o leitor real, partimos da premissa de que os procedimentos implementados na leitura literária podem ser comparados a certos mecanismos típicos das interações realizadas por meio do $\mathrm{jogo}^{3}$.

A pesquisa contou com a participação de 12 estudantes de primeiro ano do Ensino Médio de uma escola pública de Londrina, Paraná - doravante nomeados como A1 a A22 ${ }^{4}$-, os quais, sem terem lido o conto original e com pouca experiência em relação à leitura de literatura, jogaram três campanhas, em grupos distintos de quatro jogadores cada, nas quais observamos que a leitura em curso aflorava nas ações dos participantes e pôde ser "vista" através do RPG: nas antecipações, nas construções semânticas e simbólicas, nas negociações de sentido durante

\footnotetext{
${ }^{1}$ Barthes (2004) se refere ao texto criado mentalmente pelo leitor, a partir do que está escrito, em conjunto com suas vivências.

2 Por ocasião da pesquisa de Mestrado em Estudos da Linguagem, desenvolvemos esse RPG, em 2016, tomando como base um jogo de representação que já havia sido criado para as aulas de Língua Portuguesa da Educação Básica, em parceria com outros professores.

${ }^{3}$ Os dados e reflexões aqui apresentados referem-se a um recorte da dissertação de mestrado em Estudos da Linguagem, defendida na Universidade Estadual de Londrina (2018).

${ }^{4}$ Vinte e dois estudantes foram selecionados para a fase inicial da pesquisa, mas apenas doze permaneceram na fase do jogo.
} 
o compartilhamento de interpretações (COLOMER, 2009), nas manifestações da subjetividade e de afetividade (JOUVE, 2002; PETIT, 2009).

\section{Aspectos teóricos}

Como já citado, toda a nossa proposta de trabalho esteve baseada no conceito de "leitura como jogo" (PICARD, 1986 apud JOUVE, 2002, p. 111-112), do qual depreendem-se dois tipos de atividades lúdicas: o game e o playing. Este é uma alusão ao simulacro, à identificação com determinada personagem, à imersão na história; enquanto aquele refere-se às regras dadas pelo jogo/texto literário, que devem ser seguidas pelo jogador/leitor para uma compreensão adequada. Tendo em vista tais mecanismos, de acordo com Jouve (2002, p.112), "a leitura seria portanto, ao mesmo tempo, jogo de representação e jogo de regras".

A partir dessa mesma concepção, buscamos relacionar os fenômenos que ocorrem no processo da leitura com as categorias organizadas por Roger Caillois (1990) para a realização das diversas modalidades de jogos: agôn, alea, ilinx, mimicry. A primeira está relacionada aos jogos de competição, segundo o emprego original no grego. Trata-se de criar um ambiente artificial de combate, controlado e sem auxílio exterior, de modo a dar a ideia de que as oportunidades entre os competidores são equitativas, a fim de demonstrarem superioridade quanto a determinada característica: a rapidez, a força, a astúcia, a memorização etc. É o caso do xadrez, da luta e da corrida, por exemplo.

Alea, a segunda categoria, provém do termo latino para jogo de dados, ou seja, os jogos baseados na sorte. Ao contrário do agôn, a vitória não se sujeita ao jogador, já que ele sequer tem controle estratégico sobre a ação, pois seu oponente é muito menos o outro do que o acaso. Enquanto o agôn cobra disciplina e esforço individual, a alea obriga à abdicação do arbítrio. Quaisquer características individuais são postas de lado em favor de uma decisão aleatória. São exemplos desse paradigma a roleta, o jogo de cara ou coroa, a loteria etc.

O próximo grupo em que Caillois classifica os jogos é a ilinx, termo proveniente do grego, cujo significado é “turbilhão das águas”. Nele, são agrupados os chamados “jogos de vertigem”, os quais buscam "destruir, por um instante, a estabilidade da percepção e infligir à consciência lúcida uma espécie de voluptuoso pânico” (CAILLOIS, 1990, p. 43), tendo como objetivo o próprio atordoamento. Sensações como as descritas podem ser alcançadas no paraquedismo, no globo da morte, no "corrupio" (brincadeira em que a criança roda sozinha até perder o equilíbrio), em alguns brinquedos dos parques de diversões, por exemplo, o kamikaze, a roda- 
gigante, dentre outros. Figurativamente, a ilinx pode ser compreendida como aquela sensação de êxtase profundo, de delírio.

Por fim, a categoria mimicry é inspirada no mimetismo dos insetos e diz respeito à camuflagem, ao disfarce. Daí a designação, oriunda do inglês. Essa categoria trata dos jogos que se organizam em torno de um universo próprio e imaginário, em que o jogador abandona sua personalidade para assumir outra em um mundo paralelo. São exemplos de mimicry desde a brincadeira de pirata ou de cavaleiro, para a criança, até o baile de carnaval e o RPG, nosso foco neste trabalho.

A despeito do seccionamento acima, consideramos, para nossa proposta, todas as categorias de forma imbricada, envoltórias do jogo de representação e do jogo da leitura. Isso porque o RPG, ao possibilitar um contato ativo, por exemplo, com narrativas clássicas em uma primeira leitura (contextual, lexical, do enredo etc.), põe em funcionamento elementos muito semelhantes aos da leitura do texto literário, pois coloca os jogadores em função de personagens, os quais, experimentando as categorias de Caillois (1990), são responsáveis por construir a narrativa, tal qual ocorre ao leitor proficiente durante sua leitura ficcional. A ideia pode ser ainda alinhada com o conceito de leitor-personagem, de Barthes (2004), que transpõe o leitor da condição de receptor para a posição de sujeito, capaz de criar seu texto-leitura, a reescrita mental e subjetiva daquilo que foi lido, contrário à recepção passiva da obra.

Entendemos, nesse sentido, que, sendo um jogo de representação, o RPG está apto a contribuir para um ensino de leitura literária vertical, preocupado com os diferentes aspectos que envolvem a literatura, para além da compreensão primeira do enredo. Proporcionando a mimese e a catarse, simultaneamente, esse jogo trabalha como um instrumento de formação leitora e de alteridade, na medida que impele o jogador a tomar decisões no papel de outro, insere o leitor não proficiente no processo da leitura e o faz experimentar as sensações, os mecanismos e as estratégias a que o leitor proficiente já tem acesso, como a inferência, a predição, as negociações em busca do sentido (GOODMAN, 1991), a imersão no "círculo mágico" (HUIZINGA, 2000) - lugar à parte do mundo real, o universo próprio do jogo -, a experienciação do simbólico da narrativa, o vínculo afetivo com a obra (JOUVE, 2002; PETIT, 2009), entre outros. 
$O$ que é RPG?

Antes de adentrarmos as análises, façamos uma pausa para compreender em que consiste o jogo de representação de papéis. De acordo com Wagner Schmit, em sua dissertação intitulada "RPG e Educação: alguns apontamentos teóricos",

[o]s jogos de representação (JR), mais conhecidos no Brasil como RPG (Role playing
games), são atividades cooperativas nas quais um grupo de jogadores cria uma história
de forma oral, escrita ou animada, utilizando-se como plano de jogo a imaginação,
esboços, gestos, falas, textos e imagens. Cada um dos jogadores, com exceção de um,
representa uma personagem da história, com características próprias pré-definidas. O
jogador restante assume o papel de narrador (ou mestre de jogo, entre outros nomes),
sendo responsável por descrever o cenário, além de representar todos os coadjuvantes,
antagonistas e figurantes, denominados non-player characters ou mais comumente
NPC. Não existe competição direta entre os jogadores, sendo, portanto, um jogo de
socialização. (SCHMIT, 2008, p. 23).

O jogo em si é chamado de campanha, ou seja, a aventura a ser vivenciada pelos participantes. Cada campanha pode ser dividida em várias sessões - as partes da história. Por exemplo, a nossa campanha é o próprio enredo do conto A cartomante, dividida em seis sessões, que são os momentos vivenciados pelas personagens, como "A chegada ao porto", "Encontro para o chá", "Passeio de Rita e Camilo" etc. Uma campanha pode durar horas e não precisa ser jogada em um único dia. Às vezes, chega a durar meses e até anos entre os mais aficionados.

Entre os materiais necessários ao jogo, temos as fichas de personagens, blocos de anotações, dados de diferentes formatos e o Livro do Mestre. As fichas de personagens são a base para todas as ações, pois, nelas, encontram-se os atributos, as características, as perícias e habilidades de cada um, segundo sua "raça" ou função social, perfil físico e psicológico. Um rei, por exemplo, não terá os mesmos atributos de um ladrão, portanto suas habilidades e funções, no jogo, serão distintas, tal qual na vida real. Em um momento de fuga, o ladrão leva vantagem, pois está habituado a tal, assim, suas habilidades, nesse quesito, são mais desenvolvidas. Tudo gira em torno da imaginação, mas sem perder de vista a verossimilhança.

Conforme vão alcançando os objetivos, as personagens têm a possibilidade de aumentar seus pontos em determinada perícia ou habilidade e evoluir no jogo. Para isso, todos os passos, decisões, detalhes do enredo, progressos são registrados, à caneta mesmo, nas folhas individuais dos jogadores e usados em favor das próximas decisões. Assim, os jogadores tornam-se responsáveis pelo caminho que seguirão na narrativa, mas quem dá a palavra final, em diversas ocasiões, sobre o sucesso de cada um, é o Mestre, sempre fundamentado na verossimilhança diegética, pois ele tem a função de conduzir, com coesão, a mesa de jogo, narrando o enredo, 
dando opções, solicitando ações aos participantes. Às vezes, preenche lacunas interpretando personagens secundárias, apenas para manter a coerência da história (SCHMIT, 2008).

Além das características apresentadas, o RPG possibilita o uso de dados para confirmar ou não o êxito de determinadas ações, como escalar um muro alto, escapar de uma perseguição, desviar de um golpe, ludibriar ou convencer outra personagem etc. Por exemplo: certa personagem precisa fugir de um perseguidor, mas sua pontuação na perícia Fuga é baixa; ela deve tomar a decisão sobre se e como pretende fugir e jogar os dados para verificar se sua escolha obteve êxito. Esse item representa o acaso na vida real (alea), o arbítrio permeado pela sorte, como quando precisamos decidir por qual rua ir para o trabalho, mas não sabemos se a que escolhemos possui, de fato, o trânsito mais fluido naquele horário.

$\mathrm{O}$ artefato também chama a atenção pela variedade de formas. De acordo com o sistema de jogo ou a probabilidade da ação, são usados dados de diversas faces, além do comum de seis lados. Tanto para efetivar a ocorrência provável de uma decisão, quanto para determinar o dano causado a partir de uma ação, como atirar ou bater, por exemplo, os mais utilizados são os dados de quatro (D4), seis (D6), oito (D8), dez (D10), doze (D12) e vinte faces (D20).

Contudo, a aleatoriedade não é absoluta ao jogar dos dados, pois os pontos nele sorteados são comparados à pontuação previamente estabelecida de cada Característica e Habilidade nas fichas de personagens. Assim, um guerreiro que possua em sua ficha Força 10, no sistema D20, em uma situação de combate, deverá comparar sua força aos pontos tirados no dado de vinte faces. Caso o resultado seja abaixo de 10, ele terá conseguido dar um bom golpe, do contrário, o golpe não se concretizará. A lógica é que, quanto mais habilidade (pontuação) a personagem possua, menos ela dependerá da sorte para suas conquistas, como no mundo real. Esse não é o único sistema possível de uso dos dados no $R P G$, mas é um dos mais populares.

Outra peculiaridade do jogo é a preocupação com a imersão no "círculo mágico" (HUIZINGA, 2000), a fim de que o processo de fabulação tenha êxito. Para tanto, não é incomum (tampouco obrigatório) que o Mestre prepare um cenário representativo do universo ficcional, e que os jogadores se fantasiem como suas personagens, levando o mimicry às últimas instâncias.

Mesmo mantendo intacto o fio condutor da história, o jogador tem a sensação de que comanda seu destino no jogo, característica própria do RPG. Entretanto, apesar da ilusão de liberdade, além da interferência dos dados, cabe ao Mestre conduzir a história, o que lhe confere o "poder" de nortear as escolhas sem que se evidencie a manipulação. Em alguns casos, o curso 
do jogo escapa às previsões do Mestre; é quando entra em jogo sua capacidade de improviso para retomar a coesão da narrativa, a qual exige uma sequência lógica.

\section{Visualização do Fenômeno da Leitura no Jogo de Representação}

Ao analisarmos o desenrolar das campanhas, observamos que o jogo despertou nos participantes, dentro dos preceitos do playing, concordâncias e discordâncias explícitas com as atitudes das personagens originais do conto, estimulando sua criticidade, ao possibilitar o julgamento de seus próprios valores morais em contraposição aos dos papéis que representavam e às decisões dos colegas que participavam do jogo. Vejamos um exemplo disso na reação dos participantes, ainda durante o momento de leitura de suas fichas de personagem:

A19: Nossa, com essas características, eu sou a pior pessoa do mundo!” (jogadora, no papel de Rita).

A1 (no papel de Vilela): E você vai me trair, com ele ainda (apontando para A17, representante de Camilo)! Como vocês podem!?

Todas as campanhas tiveram desdobramentos muito semelhantes até momentos antes do final da narrativa. Nesta etapa, no entanto, houve muitas variações de enredo: com o primeiro grupo, Vilela mata Rita e fere gravemente Camilo, deixando-o impossibilitado de manter quaisquer relações sexuais futuras; no segundo, Vilela decide não matar ninguém, porque sua religiosidade (católica) fala mais alto, fazendo com que ele apenas abandone Rita e desconsidere Camilo como amigo; já no último grupo, Rita desconfia de que Vilela sabia de algo e volta, fugida, para o interior, enquanto Camilo é morto por Vilela com a ajuda da Cartomante. Esta havia ajudado Vilela a desmascarar os amantes, porque estava interessada na fortuna do marido de Rita, chegando ao ponto de tentar conquistá-lo, mas é rejeitada, pois Vilela entende que, por tê-lo auxiliado, a Cartomante é mau-caráter.

O resultado da última campanha mostra como as lacunas do texto podem ser preenchidas com as experiências prévias do leitor-jogador, sem fugir-lhe ao regramento, pois as interpretações dadas pelos jogadores poderiam ser, quase todas, possíveis ao desfecho do conto. Já as demais conclusões foram extrapolações à obra original, mas também mantiveram a verossimilhança baseada nas características das personagens, comprovando a eficácia do RPG como primeira leitura e preparação para o contato mais fluido e profundo com o texto original, além de revelar-se explicitador da leitura como fenômeno.

Não se pode ignorar todos os conhecimentos que estavam em jogo no momento de cada campanha, tampouco os mecanismos que entraram em funcionamento por solicitação do RPG e de sua narrativa. Observemos o exemplo da personagem Cartomante: sob o olhar do homem 
burguês do século XIX, representado, no conto, nas figuras de Vilela e Camilo, uma possível cigana, certamente, seria considerada de pouco valor, mais ainda do que sob os preconceitos de hoje. E é justamente a visão que A20, representando Vilela, direciona a essa mulher, quando, ao final da campanha, diz que não se casará com ela, por considerá-la de mau-caráter, apesar de todos os seus esforços para conquistá-lo. Segundo a fala do estudante: "se ela tentou me conquistar, sendo eu casado, e se fez de tudo para me ajudar, enganando Camilo e Rita, ela não me merece." Note-se que, em outros contextos, como em um reino medieval, com seus magos e feiticeiros, jovens como A20 chegam a admirar os "manipuladores da magia" ou os ardilosos. Também a possibilidade do relacionamento extraconjugal já é aceita em situações diferentes como a mulher que abdica de um relacionamento estável para viver um grande amor nas telenovelas -, apesar do conservadorismo que ainda permeia nossa sociedade. Mas naquele momento, o "círculo mágico" parece ter sido incorporado, e o papel masculino oitocentista foi bem desempenhado, para quem a dissolução do casamento e a traição matrimonial eram extremamente graves.

Há uma complexidade em jogo quando adolescentes do século XXI assumem personagens do século XIX e conseguem corresponder a um texto escrito nessa época. Isso nos revela dois pontos de igual interesse: o grau de sofisticação imbricado no posicionamento do aluno perante o texto adaptado e o alto nível de processamento cognitivo-afetivo que se impõe no momento da leitura. Cabe-nos destacar a relevância da experiência narrativa anterior ao jogo, escolar ou não, que demonstraram os jogadores, permitindo-lhes reconhecer as possibilidades de conclusão da diegese dentro de uma coerência proposta pelo próprio enredo. Esse jogo no interior do jogo leva-nos a perceber o requinte do processo de leitura situacional dos estudantes, bem como a pré-existência de experiência leitora, ainda que não seja de literatura canônica.

As expressões faciais dos jogadores seguem confirmando a ideia do refinamento da leitura no momento do jogo, dando indícios de que eles conseguiram entrar no "círculo mágico”. Em várias ocasiões, os estudantes que representaram Camilo, por exemplo, traziam o cenho franzido quando tinham o desafio de esquivar-se da desconfiança de Vilela, revelando preocupação em momentos tensos da narrativa. Em outras ocasiões, os representantes de Camilo e Rita usaram interjeições e expressões corporais de medo, quando estavam prestes a serem descobertos, e os que interpretaram Vilela mostraram, no olhar e na feição, a desconfiança implícita no texto.

Com relação ao nosso papel como Mestre, é importante lembrar de nossa inexperiência prática, pois poucas foram as vezes em que realmente jogamos RPG, e todas elas estavam 
ligadas a esta pesquisa. No entanto, destacamos que o conhecimento do conto, das regras gerais do jogo e do grupo de jogadores ajudou a superar algumas dificuldades, por exemplo, a necessidade de improviso na narrativa decorrente das escolhas dos outros jogadores. Ainda que tenhamos encontrado alguns obstáculos para tornar o jogo atraente, ao mesmo tempo que ferramenta de pesquisa, tais problemas parecem ter passado despercebidos pelos estudantes, dado o entusiasmo constante que todos demonstraram durante as três campanhas. Isso indica que, para mestrar uma mesa em situação de formação leitora, não é necessário ser versado no jogo como os RPGistas experientes; basta ter familiaridade com as regras do RPG, clareza dos objetivos e um bom conhecimento literário da obra em jogo, bem como do funcionamento da leitura.

Outro ponto interessante foi a representação da personagem Cartomante, que pode ser interpretada tanto como deflagradora do conflito (um dos alunos levantou a hipótese de que ela escrevia as cartas anônimas a Camilo), quanto como coadjuvante, na narrativa original, usada por Camilo e Rita para confirmar um desejo e uma ação anteriores a ela: a manutenção de seu envolvimento amoroso e da relação de ambos com Vilela (de amizade e matrimonial, respectivamente). O fato é que, mesmo sem ler o conto, a condição da Cartomante foi percebida e respeitada pelos jogadores, os quais assumiram seus papéis de maneira coerente, dentro das possibilidades oferecidas.

Dadas essas percepções gerais, podemos elencar alguns eixos que emergiram das campanhas de RPG. Sendo assim, para efeito de análise, agrupamos em três tópicos os elementos observados, constituintes da leitura: A leitura literária como jogo; O papel da afetividade na prática leitora, e Negociações de sentido na leitura compartilhada.

\section{A leitura literária como jogo}

Em consonância com as discussões realizadas até aqui, o fio condutor da pesquisa foi a comparação dos elementos constitutivos do fenômeno da leitura com os do jogo. O que faremos, nesta seção, é demonstrar como a leitura observada nas campanhas de RPG reproduz vários elementos compatíveis com a leitura literária. Para isso, deixemos claro que estamos lidando com dois diferentes tipos de textos: um é o roteiro do jogo, baseado em A Cartomante; o outro é o próprio conto, texto literário, de estrutura muito diversa, mas ambos com pontos de semelhança entre si.

Ao observar todos os grupos na prática do jogo, verificamos que os conceitos estudados como aporte teórico se concretizaram no RPG e como componentes da leitura. A alea (sorte), 
a ilinx (vertigem), a mimicry (representação) e o agôn (competição), de Caillois (1990); o game (regramento) e o playing (envolvimento), de Jouve (2002); e o "círculo mágico" (universo do jogo/literário), de Huizinga (2000), todos, de alguma forma, circundaram a nossa pesquisa de campo, bem como suas análises. O mesmo ocorreu com os conceitos literários "primeira e segunda leitura", de Barthes (2015) ou "leitura inocente/leitura crítica", de Jouve (2002), cuja efetivação constatamos no jogo.

Na primeira campanha, da qual participaram exclusivamente meninos (A15, A16, A18 e A22), notamos um fato peculiar: as personagens femininas Cartomante e Rita foram muito bem incorporadas pelos jogadores, de forma divertida e sem nenhum desconforto. Ao contrário, isso contribuiu para uma imersão mais profunda no "círculo mágico", pois os papéis, sendo de gêneros distintos dos seus, exigiram maior atenção e cuidado na interpretação. Nesse momento, entraram em cena a mimicry (representação do papel solicitado), o game (respeito às normas do texto) e o playing (envolvimento com a narrativa):

\footnotetext{
A22: Eu sou mulher. Eu sou transexual?

Professora: Não, essa é uma mulher convencional.

A22: Entendi. Então agora eu sou a Rita.
}

Os três conceitos presentes no diálogo, por estarem empiricamente ligados, figuraram em todas as campanhas, entretanto, nem sempre destacaremos os três, para evitar repetições. No caso acima, notamos o empenho do aluno em entender o texto e suas normas (game) para cumprir adequadamente seu papel (mimicry), alcançando um genuíno envolvimento com a história (playing) e adentrando deveras na narrativa (círculo mágico), segundo veremos, com maior clareza, em outras passagens. Algumas vezes, em nossa análise, mimicry, playing e "círculo mágico" podem ter linhas de distinção muito tênues, porque são parte do mesmo processo, tanto no jogo, como na leitura literária.

Outro exemplo disso é a performance de A11 durante o jogo, quando no papel de Cartomante. Imersa no "círculo mágico" (HUIZINGA, 2000) e levando o playing a um nível elevado, engendrou um plano de conquista a Vilela, unindo-se a ele em seu propósito de desmascarar os traidores, para o que fez falsas previsões ao casal de amantes e os enviou à morte, em um gesto de apoio ao magistrado, ao mesmo tempo que tirava a esposa de seu caminho. Observa-se aí a profundidade da interpretação da estudante, plenamente verossímil em relação à narrativa original, portanto filiada ao game, demonstrando o quanto o RPG tem a capacidade de despertar a sofisticação interpretativa, mesmo nos leitores não proficientes. 
Recorrentes são também a "leitura inocente" e a "leitura crítica", as quais permeiam todas as campanhas e o grupo focal. Enquanto os jogadores do primeiro grupo, por exemplo, liam suas fichas de personagens, pudemos visualizar o florescimento da "primeira leitura" (BARTHES, 2015) ou, nas palavras de Jouve (2002), da "leitura inocente", em que o prazer é mais proeminente, devido à curiosidade, às antecipações e às descobertas:

A18: Eu já sei que eu vou morrer, eu já sei que eu vou morrer... (lendo sua ficha, no papel de Camilo)

Professora: Você não vai morrer, a não ser que você escolha algum caminho que leve a isso ou dê azar.

A18: Olha só, eu sou CAÓTICO...

Professora: É... em relação ao bem e mal, você é neutro, para você tanto faz.

A22: Eu sou INDECISO?! (Papel de Rita).

Professora: É... Você vai pela situação. Se precisar escolher entre bem e mal, você escolhe o mal para conseguir o que quer.

A22: Pessoal, eu sou horrível!

A18: Então assim... ele (apontando para A22) não pode escolher o bem, já que...

Professora: Não, não é que ele não pode, é que ele é INDECISO, então algumas vezes vai escolher, outras não. Depende do momento, porque o INDECISO não está preso a um princípio.

A18: Ah. Mas então ele vai escolher o mal quase sempre, né?

Nota-se, no diálogo, o entusiasmo e algumas dificuldades de A18 e de A22 em relação ao léxico a partir de suas caracterizações, o que é análogo ao que ocorre durante a primeira leitura do texto literário. Percebe-se que seu conhecimento restrito do vocabulário próprio do RPG solicita o auxílio da professora, em alguns casos, como no que tange às palavras "caótico" e “indeciso", cujos significados, no jogo, têm certas diferenças do habitual. No entanto, há momentos de avanço para uma leitura crítica do texto do jogo, demonstrando que uma leitura mais profunda da obra literária também pode ser alcançada pelo leitor não proficiente, com mediação do professor. Prova disso é que A18 deduz, coerentemente, sobre sua morte, ao ler que sua personagem tende ao caos, e conclui que a personagem do colega, não tendo princípios, não vai escolher o bem, segundo os valores sociais que ele conhece.

No trecho abaixo, temos novamente alguns componentes da "leitura crítica", referentes ao contexto da obra, o século XIX:

A15 (papel de Vilela): Meu objetivo vai ser separar de você (a Rita), cara! A22 (papel de Rita): Mas se eu separar de você, você perde sua honra... porque separou da esposa... O que vai acontecer? Ele (apontando para o aluno que faz o papel do Camilo) vai tentar me seduzir, então eu vou atuar contra você (apontando para o aluno que faz papel de Vilela, já pensando na estratégia para o jogo).

Observamos, no fragmento, a consistência com o pensamento do período em que o texto está ambientado, no eixo família-honra. Há, portanto, um respeito ao game, já com a ativação do playing, pois percebe-se um envolvimento do leitor-jogador com o que leu. Verificamos 
ainda o emergir do agôn, mesmo que o RPG não seja um jogo de competição direta. A competição aparece, nesse caso, como algo que está no cerne do comportamento humano, destarte, no plano do jogo e no plano da diegese: tanto ocorre entre os jogadores, quanto entre Vilela e Camilo.

No próximo exemplo, o jogador mantém a coerência com o que compreende ser a característica principal de sua personagem: a honra, demonstrando ter conseguido adentrar totalmente na narrativa:

A15: Eu não vou cobrar a dívida de Camilo, porque sou um homem de palavra, leal! (jogador no papel de Vilela, justificando sua ação em referência às próprias características no jogo).

Como na leitura literária, o game e o playing continuam ocorrendo concomitantemente e convergem sempre para o "círculo mágico". Vemos que, uma vez colocadas em prática as fichas das personagens, em todos os grupos, as ações dos jogadores variam, mas ainda ficam restritas ao caráter requisitado de cada papel, evidenciando que os estudantes têm competência para seguir o regramento do texto e, ao mesmo tempo, envolverem-se nele, até ir além. Em determinados momentos, houve releituras de certas ações descritas no texto original, por serem entendidas pelos participantes como mais condizentes com a personalidade de sua personagem do que o que está narrado no conto. Nesse quesito, um comentário destacável foi:

\footnotetext{
A1: Na época eles não eram muito católicos no Brasil? Então, como eu sou muito correto e nos dez mandamentos fala que não pode matar, não vou matar ninguém. $\mathrm{O}$ Camilo não é mais meu amigo e vou me separar da Rita (jogador no papel de Vilela, já no final da campanha).
}

A mimicry entra em funcionamento na postura de A1, pois ele interpreta seu papel, dando vida à sua personagem, após procurar fazer a leitura de todo o contexto. Durante a campanha do Grupo 3, no momento em que Camilo recebe a notícia do falecimento de sua mãe, além dos elementos já citados, também se destaca a mimicry:

Mestre: Camilo recebe uma notícia muito desagradável, que é o falecimento de sua mãe.

A3: (Interpretando Camilo, exibe uma expressão facial de surpresa mesclada à tristeza, que permanece durante todo o diálogo sobre esse assunto).

Mestre: Vilela, a mãe de Camilo acaba de falecer e ele está arrasado. O que você faz? A decisão é livre, sem necessidade das cartas.

A20: Eu ajudo meu amigo, com certeza.

Mestre: Ajuda como?

A20: Eu faço um empréstimo pra ele, cobrindo as despesas do funeral e do enterro, que pode ser pago com trabalho pra mim, ajudando a arrumar meu novo escritório.

Mesmo sem ter lido o conto, parte da decisão de A20 é muito parecida com a da personagem da obra original, e parte segue a lógica da interpretação do aluno, que entendeu o 
magistrado como alguém bom e fiel ao amigo, mas sempre ligado às questões financeiras, pois foi assim que conseguiu fazer sua fortuna. Isso não foge à verossimilhança do conto, o qual pode deixar subentendido que Vilela é sisudo, comedido, talvez mesquinho. A mimicry é muito evidente nesse momento do jogo, em que o aluno busca incorporar, ao máximo, as características de sua personagem, tentando seguir, à risca, o que entende ser compatível com o comportamento do papel que desempenha na história. Manifesta, assim, seu comprometimento com o game (regramento semântico do texto), que o leva ao playing e, consequentemente, ao mergulho no "círculo mágico".

As expressões faciais de A3 e de A20 também são destacáveis como elementos da mimicry, revelando que ambos realmente assumiram suas personagens para bem desenvolvêlas na narrativa. As demonstrações de tristeza com a morte da mãe e de superioridade com a ajuda que prestará ao amigo, de A3 como Camilo e de A20 como Vilela, respectivamente, marcam suas imersões no "círculo mágico", bem como sua chegada ao estágio do playing, por meio do respeito ao game.

A alea (sorte) permeou diversos momentos da atividade lúdica, tal qual a ilinx (vertigem), contudo ambas foram mais perceptíveis nas ações dos jogadores do que em seus discursos, por isso nos é quase impossível reproduzir exemplos. Podemos, no entanto, descrever a alea no plano da diegese, do jogo e da leitura: no instante em que Camilo vai ao encontro de Vilela e o acaso faz com que sua carruagem pare em frente à casa da Cartomante; ou quando o jogador, no papel de Camilo, precisa decidir entre atender ou não ao chamado do amigo, sem saber se ele conhece sua deslealdade; ou ainda no caso do leitor, que deve seguir na narrativa, contando com a sorte para que suas expectativas sobre a ignorância de Vilela quanto à infidelidade da esposa e do amigo sejam cumpridas. A segunda descrição ocorreu em todos os grupos de RPG, pois aos participantes não era revelado se a personagem de Vilela desconhecia ainda a traição de Camilo e Rita ou se estava apenas disfarçando sua ciência do fato para vingar-se mais tarde, como no conto. Por conseguinte, as personagens de Camilo e de Rita sempre traçavam suas estratégias baseadas na alea.

Quanto à ilinx (vertigem), esta foi muito perceptível no entusiasmo do primeiro grupo. De fato, houve um arrebatamento dos participantes desde a leituras das fichas.

A15 (papel de Vilela): Nossa, eu tenho 14 de arma de fogo! (referindo-se a sua pontuação na ficha de personagem).

Pesquisadora (o Mestre): É, vai ter o momento da arma de fogo, que você vai poder usar, se quiser...

A15 (papel de Vilela): Oow! (animado). 
Essa empolgação permaneceu e se elevou a cada decisão, conforme avançávamos na narrativa, de modo equivalente à sensação do leitor proficiente diante de uma obra que o extasia. Tamanha foi a força da ilinx para esse grupo, que os mesmos alunos chegaram a voltar, horas depois de terminadas suas participações, para assistir às campanhas dos demais grupos, talvez em busca do mesmo efeito, porém, agora, como espectadores. Com base nessa experiência, podemos afirmar que a ilinx é o grau máximo do playing.

\section{O papel da afetividade na prática leitora}

O comparecimento da afetividade no jogo foi tão constante, que se faz inviável transcrever aqui a totalidade das situações em que ela se revelou. Na seção anterior, todas as vezes em que demonstramos o playing e o "círculo mágico", poderíamos identificar também a afetividade. Do mesmo modo, na próxima seção, ao discutirmos o compartilhamento, é preciso ter em conta as relações marcadamente afetivas ali presentes.

Sendo a leitura comparável ao jogo, a afetividade se mostra também característica essencial a ambos, e pudemos comprovar essa afirmação na prática lúdica. Logo, destacamos alguns excertos além dos que já foram analisados, em que a dimensão afetiva se sobressaiu, enquanto o aluno-leitor participava da narrativa como "leitor-personagem", tornando visível, no RPG, o conceito formulado por Barthes (2004).

Vejamos o caso de A21, que, ao ler sua ficha, comparou as características requisitadas por seu papel às próprias e concluiu: "Eu sou perfeita para esse personagem." Sua vinculação com a narrativa, por meio da personagem que representaria, ocorreu de imediato, facilitando seu processo de imersão na diegese. Não nos esqueçamos, porém, de que a afetividade não evoca apenas sentimentos positivos, pois refere-se ao modo como algo nos afeta. É possível que nos envolvamos negativamente com a obra, ao rechaçar certos comportamentos ali inscritos, conforme ocorreu com A22: "Pessoal, eu sou horrível".

Vale ressaltar que ambos estão reagindo à mesma personagem (Rita), mas a repulsa de A22 não o impediu de participar do "círculo mágico", envolto na ilinx, segundo já discutimos. Os dois jogadores se sentiram ligados à narrativa, porque lhes foi dado o direito de ter voz sobre ela. Houve espaço para compararem as personagens às próprias vidas, o universo literário ao próprio mundo, diferentemente do que se passa em uma "prova do livro", em que, em geral, o aluno não é requisitado em sua subjetividade.

A seguir, destacamos os diálogos realizados após o jogo, com a verbalização desse sentimento: 
Professora: Como foi jogar RPG?

(Expressões de entusiasmo, no geral)

A3, A11, A14 e A17: Foi muito legal!

A1 e A22: (Sinais de "joia", com expressões de alegria)

A19: Ah, eu adorei! Professora, nós concordamos aqui, se você vendesse esse jogo, a gente compraria.

A20: Foi muito interessante você passar a história pra RPG, foi muito interessante... Me deu vontade de jogar mais.

A15: Foi emocionante! Eu me animei bastante, foi legal!

Professora: Ok. Vocês me disseram que gostaram de jogar RPG. E da história, em si, o que vocês acharam? Daquele enredo?

A19: Ah, eu gostei bastante! Eu até fiquei tão curiosa, que quando eu cheguei em casa, já fui pesquisar pra ler.

A20: Eu achei muito original.

A19: Eu gostei da minha versão!

Curiosidade sobre o conto e desejo de posse em relação ao jogo, ambos traduzem a constituição da afetividade, na medida em que expressam uma carga marcadamente subjetiva sobre o objeto. Em seguida, entusiasmo e emoção, como elementos da ilinx, reforçam-na. Com todas essas sensações em movimento, o tex to do jogo pôde ser incorporado pelos estudantes de uma maneira muito mais fluida, afinal, eles vivenciaram a história enquanto "leitorespersonagens", trazendo à tona o "texto-leitura" (BARTHES, 2004). Na última fala de A19, isso se evidencia, pois ela demonstra o vínculo positivo com a história que construiu, por meio de sua participação na narrativa.

Ao mencionar a originalidade, A20 provavelmente se refere ao que eles estão acostumados a jogar ou a ler. Revela-se, em seu discurso que, mesmo sendo um enredo alheio aos costumeiros gostos juvenis, como as sagas da moda, A Cartomante é potencialmente atrativo e envolvente também na adolescência, tal qual outros clássicos, dependendo da forma como são apresentados ao jovem leitor.

O próximo fragmento segue descrevendo com lucidez o fenômeno da leitura literária como processo de envolvimento e de criação do leitor:

Professora: Qual a diferença entre jogar e ler a história?

A20: Jogar é muito mais interessante e divertido, porque você pode conduzir a história do seu jeito, se você souber conduzir a história.

A15: É que no jogo, a gente meio que incorpora o personagem, você fica meio que... você se sente personagem. A escolha que você vai fazer, vai interferir no futuro da história. Isso que é legal! Isso é muito bom!

A1: A gente meio que se envolve mais na história do que numa leitura, dependendo da pessoa.

A22: Você não passa a ler e interpretar, você passa a criar.

A14: Ah, depende da pessoa. Ela (apontando para A19), por exemplo, é acostumada a ler, então...

A19: É que é assim: tem o personagem principal [no livro] e eu viro o personagem principal; eu vou lendo, parece que aquilo acontece comigo, por isso que eu amo livro... 
A14: É o que ela falou... Ela lê desde criança. A gente não. Quando a gente lê é forçado, sem se entregar...

É evidente que a maioria dos alunos, ao avaliar seu desempenho no RPG, transfere para o jogo grande parte dos atributos da literatura, como o envolvimento afetivo de que estamos tratando, porque, para eles, talvez, a leitura plena ainda está muito distante. A22 utiliza, inclusive, "ler e interpretar" como sinônimos de decodificar e entender passivamente. A criação não estaria a cargo do leitor literário, segundo sua visão. Já A1 e A14 colocam em dúvida essa afirmação e apontam a colega A19 como alguém que foge a esse "padrão" de leitor inerte. A19, por sua vez, aproveita para expor sua experiência e prova que o discurso do "jogo como única forma de incorporar a personagem" é falso. Nesse diálogo, mesmo sem conhecimento teórico, os estudantes tangenciam o conceito de leitor-personagem, postulado por Barthes (2004).

Mais adiante, quando questionamos sobre a leitura espontânea do conto, apenas duas alunas se manifestaram. Os demais apresentaram como motivo para a não leitura: as avaliações finais, "cinco trabalhos para entregar no mesmo dia", "pouco tempo 5". Perguntamos, então: "se estivéssemos em uma situação letiva regular, vocês leriam o conto?" Obtivemos as seguintes respostas:

\begin{abstract}
A20: Eu leria, porque eu me interessei pelo final que construí e eu gostaria de saber o final original da história.

A3: Eu leria, por causa que eu fiquei curioso.

A19: Eu leria de qualquer jeito, mas eu entendo o ponto de vista deles, porque é uma história meio antiga. Normalmente, não é todo mundo que se interessa por leitura, vamos começar por aí. E, geralmente, quem gosta de leitura, tem um gênero específico que gosta de ler e, às vezes... ah, é porque é antiga, não quero ler. Só que, tipo assim, como você introduziu [a história do conto] no jogo e ficou bem divertido, ficou um clima mais "vamos ler!".
\end{abstract}

Mais do que o leitor-personagem apontado implicitamente por A20, sobressai-se, nesse trecho, a ideia do leitor real, que sugerimos ser considerado nas aulas de leitura. Enquanto A3, de certa forma, e A20, sentindo-se participantes da narrativa, quiseram saber o que o outro (autor) fez de "sua" história, A19 verbaliza, com espontaneidade, que o leitor adolescente, ainda mais do que o adulto, necessita desse vínculo com a leitura, seja pelo tema (antigo ou moderno), seja por meio da metodologia de ensino. Como o conto base do jogo tem, pelo menos, 130 anos e foi bem aceito pelos participantes da pesquisa, concluímos que o método é ainda mais importante do que a temática para cultivar o interesse do leitor real em formação.

$5 \mathrm{O}$ momento histórico realmente foi delicado, pois estavam ocorrendo protestos contra o "Ensino Médio Inovador", do Governo Federal, com a ocupação da escola pelos estudantes, e a aplicação da pesquisa coincidiu com volta às aulas repleta de avaliações em atraso. 
Assim, o RPG veio em nosso auxílio ao suscitar a afetividade que, apesar de despontar com os primeiros livros da infância, acaba negligenciada ao longo do processo escolar. A paixão com que os estudantes se debruçaram sobre a história de A Cartomante enquanto jogavam, a energia que empregaram na leitura das fichas de personagens e a atenção espontânea que deram à leitura do Mestre (muitas vezes, não dispensada à aula) são provas de que a literatura canônica pode despertar o interesse e a afetividade dos jovens, desde que isso seja desenvolvido com eles por meio de instrumentos adequados.

\section{Negociações de Sentido na Leitura Compartilhada}

Durante todas as campanhas de RPG e no debate com os alunos, o tipo de leitura mais evidente e enaltecido pelos sujeitos desta pesquisa foi a leitura compartilhada (COLOMER, 2009), pois, em todo o processo, a significação do texto em jogo construiu-se pelo grupo, na coletividade. As três equipes fizeram antecipações do enredo já no princípio das atividades com o RPG, apenas lendo as fichas das personagens e compartilhando suas caracterizações fictícias com os colegas. Ao observar certa informação sobre o papel que desempenharia, como o fato de ser uma "esposa carente" (Rita), o participante já inferia que haveria um marido displicente e, possivelmente, um amante na história. Na sequência, fazia a divulgação da característica no grupo, ao que os colegas retornavam com seus próprios atributos, confirmando as hipóteses do jogador que previu o enredo. Esse fato foi recorrente em todas as campanhas do jogo, e na primeira, ainda no momento das instruções, encontramos um episódio exemplar da relevância do compartilhamento na formação leitora. Vejamos a transcrição do diálogo:

\footnotetext{
A15 (papel de Vilela): Nossa, eu tenho 14 de arma de fogo! (referindo-se à sua pontuação na ficha de personagem).

Pesquisadora (o Mestre): É, vai ter o momento da arma de fogo, que você vai poder usar, se quiser...

A15 (papel de Vilela): Oow! (animado).

A22 (papel de Rita): "Eu tenho certeza que você vai apontar essa arma pra mim. Eu tenho certeza!

A18 (papel de Camilo): Ou é eu (querendo dizer que ele levaria o tiro).

A15 (papel de Vilela): Meu objetivo vai ser separar de você (a Rita), cara!

A22 (papel de Rita): Mas se eu separar de você, você perde sua honra... porque separou da esposa... O que vai acontecer? Ele (apontando para o aluno que faz o papel do Camilo) vai tentar me seduzir, então eu vou atuar contra você (apontando para o aluno que faz papel de Vilela, já pensando na estratégia para o jogo). Professora, já estamos filosofando e o jogo nem começou!
}

Não seria possível aos participantes fazerem tantas previsões específicas sobre o enredo unicamente com a leitura da própria ficha, mas a partir da junção das características das personagens, como "habilidade em arma de fogo" para o marido, "carência" para a esposa e 
"carisma" para o melhor amigo do marido, todos, sem exceção, conseguiram deduzir a existência de um triângulo amoroso e antecipar uma tragédia na narrativa. Vale ressaltar a sagacidade interpretativa de A22, quando se posiciona como alguém do século XIX e levanta a questão da honra relacionada à manutenção do casamento, vendo aí uma oportunidade de desestabilizar seu colega de jogo. Foi o compartilhamento que possibilitou essas interpretações, impelindo ao prosseguimento verossímil das ações no RPG e à organização das estratégias para o alcance dos objetivos. A partir do compartilhamento de suas leituras das fichas, os jogadores conseguiram ser coesos e manter a sequência lógica do texto.

O episódio transcrito comprova a necessidade humana da leitura compartilhada, defendida pela pesquisadora espanhola Teresa Colomer (2009), pois, segundo ela, "a leitura se relaciona sempre de alguma maneira com as atividades compartilhadas", uma vez que "a reflexão educativa já assinalou que o sentimento de pertencer a uma 'comunidade interpretativa' é o mecanismo básico para aprender a desfrutar de formas literárias mais elaboradas" (COLOMER, 2009, p. 148). Nos moldes do que defende Colomer (2009), os leitores-jogadores puderam beneficiar-se das interpretações de seus pares para construírem as próprias, ao mesmo tempo em que contribuíam para novas interpretações no jogo, em um movimento cíclico de leitura $^{6}$, no sentido etimológico da palavra. Também por meio do compartilhamento, pudemos observar, de forma mais evidente no RPG do que conseguiríamos em uma prática de leitura tradicional, a construção coletiva de seu texto-leitura (BARTHES, 2004) pelos leitores-jogadores, embora, em ambas leituras, o produto textual seja de origem coletiva, em maior ou menor grau.

Outro exemplo da eficácia do compartilhamento pôde ser observado no grupo 3, quando, no início da campanha, uma das jogadoras enfatizou sua personalidade no universo fictício:

A21: Eu sou uma esposa carente. Esposa de quem?

Pesquisadora (o Mestre): Isso. Você é a esposa do Vilela.

A21: Ah, tá. Eu sou sua esposa (dirigindo-se ao colega).

Pesquisadora (o Mestre): É. Ela é sua esposa (voltando-se ao jogador no papel de Vilela). É uma esposa carente, porque ele [Vilela] é um magistrado que trabalha pra caramba... muito preocupado com o trabalho e não dá tanta atenção à esposa.

A20: Então você vai me trair, tá na cara... (dirigindo-se à jogadora no papel de Rita, em tom recriminador).

Pesquisadora (o Mestre): E o Camilo é...

A20: E com ele ainda [vai me trair]? (Aqui o jogador imprime à constatação um tom de indignação, colocando as mãos na cabeça).

A3: (No papel de Camilo, o jogador ri, com expressão pilhérica e ar de malandragem. Todos da mesa riem com ele).

A20: Já entendi esse casamento...

\footnotetext{
${ }^{6}$ Leitura origina-se do radical latino legere, cujo significado é a ação de escolher, juntar e colher (não coletar) o significado.
} 
Nota-se, no diálogo acima, a naturalidade com que os jogadores fazem inferências a partir das informações apresentadas pelo outro, bem como o prazer de partilhar do entendimento do texto com o grupo, conforme a pesquisa de Colomer (2009). Além disso, no RPG, cada vez que um jogador revelava sua interpretação do texto lido, mais os outros adentravam no "círculo mágico" e incorporavam seus papéis. Pode-se argumentar que a leitura individual do texto original proporcionaria as mesmas predições, contudo, há que se recordar que estamos tratando de leitores não proficientes, diante de uma linguagem literária bastante elaborada, ao estilo machadiano. Ademais, as caracterizações "carente, workaholic e bon vivant", para Rita, Vilela e Camilo, respectivamente, fazem parte também de um compartilhamento de leitura, dessa vez do Mestre, nosso papel no jogo, ou seja, da professora em uma posição diferente daquela que ministra um conteúdo. Esse arranjo, no conjunto do jogo, permite que os estudantes se sintam construtores do texto, não meros ouvintes ou receptores, como ocorreria se o educador simplesmente relatasse o enredo da obra.

Trabalhado no grupo, o texto clássico, com seu vocabulário considerado difícil pelos estudantes e sua temática, aparentemente, distante deles, deixou de ser impedimento para a fruição na leitura, ratificando que o prazer de ler pode e deve ser ensinado na escola com estímulo coletivo. Por meio do jogo, os alunos alcançaram o prazer de superarem, juntos, as dificuldades daquele texto (que também são inerentes ao literário), o prazer de se sentirem pertencentes a uma comunidade de leitores (COLOMER, 2009).

O compartilhamento experienciado no RPG, apesar de não ser um elemento da leitura, mas um tipo, é muito importante, à medida que favorece o desenvolvimento cognitivo e socioafetivo do leitor em formação. Essa atividade leitora é a mesma de que sentem falta os leitores não proficientes, pois deixam bem claro que suas ações ainda se pautam na coletividade. Ao leitor maduro, ler sozinho pode ser suficiente, mas mesmo para este, o ato de compartilhar as próprias formulações com um grupo traz novas percepções da obra e de si mesmo. Com o RPG, é possível vivenciar esse senso de pertencimento a uma comunidade de leitores e construir novas significações do texto ainda no início da formação leitora. Afinal, como assinala Colomer (2009, p. 143), ler coletivamente dá "uma intensa sensação de possuir um instrumento que se harmoniza com o entorno". Proporcionando o compartilhar de leituras, de saberes, de vivências, estamos favorecendo a que os estudantes aproveitem essa ação em benefício do próprio desenvolvimento. 


\section{Considerações Finais}

Enxergar os elementos que compõem a leitura é importante porque contribui para a melhoria do processo de formação de leitores na escola, dado que só é possível elaborar estratégias para auxiliar os estudantes a aperfeiçoar seus mecanismos de leitura se entendemos como eles leem.

A proposta de trabalho com o RPG como introdução à leitura da obra literária revelou-se eficaz, na medida em que instigou e motivou parte dos alunos participantes da pesquisa a buscar a leitura do texto de Machado de Assis, a despeito de se tratar de uma literatura muitas vezes considerada fora do alcance ou do interesse do adolescente.

Ademais, a pesquisa evidenciou vários pontos de contato fundamentais entre os fenômenos do jogo e da leitura, o que proporcionou reflexões a respeito das metodologias a serem implementadas na formação de leitores de literatura na escola básica.

\section{Referências}

ASSIS, Machado. A cartomante e outros contos. São Paulo: Ed. Moderna,1995.

BARTHES, Roland. O rumor da língua. Tradução de Andréa Stahel M. da Silva. 2. ed. São Paulo: Martins Fontes, 2004.

BARTHES, Roland. O prazer do texto. Tradução de J. Guinsburg. São Paulo: Perspectiva, 2015.

CAILLOIS, Roger. Os jogos e os homens: a máscara e a vertigem. Tradução de J. G. Palha. Lisboa: Cotovia, 1990.

COLOMER, Teresa. Andar entre livros: a leitura literária na escola. São Paulo: Global, 2009.

GOODMAN, Kenneth. Unidade na leitura: um modelo psicolinguístico transacional. In: Letras de Hoje, Porto Alegre, v. 26, n. 4, p. 9-43, dez. 1991. Disponível em:

<http://revistaseletronicas.pucrs.br/ojs/index.php/fale/article/view/16125> Acesso em: 05 maio 2016.

HUIZINGA, J. Homo ludens: o jogo como elemento da cultura. Perspectiva: São Paulo, 2000.

JOUVE, Vincent. A leitura. Tradução de Brigitte Hervot. São Paulo: UNESP, 2002.

PETIT, Michèle. Os jovens e a leitura: uma nova perspectiva. Tradução de Celina Olga de Souza. São Paulo: Editora 34, 2009.

SCHMIT, Wagner Luiz. RPG e Educação: alguns apontamentos teóricos. 2008. Dissertação (Mestrado em Educação). Universidade Estadual de Londrina, Londrina. Disponível em: 
<http://www.uel.br/pos/mestredu/images/stories/downloads/ dissertações/2008/2008\%20\%20SCHMIT,\%20Wagner\%20Luiz.pdf>. Acesso em: 13 abr. 2020.

Recebido em: 29/04/2020 Aceito para publicação em: 18/08/2020 